\title{
Inter-kingdom signalling: communication between bacteria and their hosts
}

\author{
David T. Hughes and Vanessa Sperandio \\ Department of Microbiology, University of Texas Southwestern Medical Center, Dallas, Texas \\ 75235, USA.
}

\section{Abstract}

Microorganisms and their hosts communicate with each other through an array of hormonal signals. This cross-kingdom cell-to-cell signalling involves small molecules, such as hormones that are produced by eukaryotes and hormone-like chemicals that are produced by bacteria. Cell-to-cell signalling between bacteria, usually referred to as quorum sensing, was initially described as a means by which bacteria achieve signalling in microbial communities to coordinate gene expression within a population. Recent evidence shows, however, that quorum-sensing signalling is not restricted to bacterial cell-to-cell communication, but also allows communication between microorganisms and their hosts.

Prokaryotes and eukaryotes have coexisted for millions of years. It is estimated that humans have $10^{13}$ human cells and $10^{14}$ bacterial cells (comprising the endogenous bacterial flora). Eukaryotes have a variable relationship with prokaryotes, and these interactions can be either beneficial or detrimental. Humans maintain a symbiotic association with their intestinal microbial flora, which is crucial for nutrient assimilation and development of the innate immune system ${ }^{1}$. These mutually beneficial associations are possible because microorganisms and mammals can communicate with each other through various hormone and hormone-like chemical compounds. These signals, however, can be 'hijacked' by bacterial pathogens to activate their virulence genes.

The hormonal communication between microorganisms and their hosts, dubbed inter-kingdom signalling, is a recent field of research. This field evolved from the initial observation that bacteria can communicate with each other through hormone-like signals ${ }^{2}$, a process that was later named quorum sensing $(\mathrm{QS})^{3}$. This field expanded with the realization that these bacterial signals can modulate mammalian cell-signal transduction ${ }^{4}$ and that host hormones can crosssignal with QS signals to modulate bacterial gene expression ${ }^{5}$.

In this Review, we discuss several mechanisms that are used for hormonal communication between micro-organisms and their hosts. Owing to space constraints, we mainly consider pathogenic interactions. We focus primarily on acyl-homoserine lactones (AHLs) and aromatic (autoinducer (AI)-3) signals, because of the wealth of reports that link these signals to interkingdom communication, but it is worth noting that bacteria use an array of additional chemical

Correspondence to V.S. e-mail: vanessa.sperandio@utsouthwestern.edu.

DATABASES

Entrez Genome Project: http://www.ncbi.nlm.nih.gov/entrez/query.fcgi?db=genomeprj Agrobacterium tumefaciens | Borrelia burgdorferi | Escherichia coli | Francisella tularensis | Medicago truncatula | Providencia stuartii | Pseudomonas aeruginosa | Salmonella typhi | Salmonella typhimurium | Sinorhizobium meliloti | Vibrio fischeri | Vibrio parahaemolyticus

FURTHER INFORMATION

Vanessa Sperandio's homepage: http://www.utsouthwestern.edu/utsw/cda/dept131456/files/159676.html 
molecules to communicate with one another, and it is expected that future research will implicate these in inter-kingdom signalling. After discussing bacteria-mammal and bacteriaplant interactions, we will discuss the evolutionary parallels between host and microorganism signalling systems.

\section{The hormonal signals}

There are three broad categories of mammalian hormones: proteins (or peptides), steroids (a subclass of lipidic hormones) and amino-acid derivatives (or amines). The structure of a hormone dictates the location of its receptor. Amine and peptide hormones cannot cross the cell membrane and bind to cell-surface receptors (such as receptor kinases and G-proteincoupled receptors (GPCRs)), whereas steroid hormones can cross plasma membranes and primarily bind to intracellular receptors.

Protein and peptide hormones constitute most of the hormones, contain 3-200 amino acids and are usually post-translationally processed. Peptide hormones include the epidermal growth factor (EGF), insulin and glucagons. Steroid hormones are derived from cholesterol, and amines are synthesized from tyrosine. Amine hormones include the catecholamines adrenaline, noradrenaline (NA) and dopamine ${ }^{6}$. All of these hormones (FIG. 1) are engaged in interkingdom signalling with microorganisms.

\section{Communicating through cell-surface receptors}

Here, we summarize signalling through mammalian and bacterial extracellular receptors that recognize hormones that do not cross the cellular membrane. Owing to the abundance of reports on inter-kingdom signalling through intracellular receptors, these signalling mechanisms will be discussed separately.

\section{Signalling through receptor kinases}

Receptor kinases are cell-surface receptors that possess intrinsic tyrosine- or threonine-kinase activity that becomes activated upon the binding of a hormone to the extracellular aminoterminal region of the receptor. This activation results in the recruitment and phosphorylation of intracellular downstream proteins, which initiates signalling cascades (FIG. 2). One receptor tyrosine kinase that is important for host-microorganism communication is the EGF receptor (EGFR). EGFR exists on the cell surface and is activated by the binding of EGFs, small proteins that are widely used as signals by animal cells ${ }^{7}$. Upon activation by EGF, EGFR undergoes a transition from an inactive monomeric form to an active homodimer, which stimulates the intrinsic intracellular tyrosine-kinase activity of EGFR. Autophosphorylation results in downstream activation and signalling by other proteins, which initiates the signal-transduction cascades, principally the mitogen-activated protein kinase (MAPK), Akt and Jun aminoterminal-kinase (JNK) pathways, that lead to DNA synthesis and cell proliferation. EGFR signalling is required for cell-fate specification, growth and survival at multiple steps of development ${ }^{7}$ (FIG. 2).

The membrane serine protease rhomboid (Rho) regulates EGFR signalling by allowing the secretion of EGFR ligands through the proteolytic activation of EGF from the signal-emitting cells, and provides a link between eukaryotic signalling and host-microorganism communication (TABLE 1). Rho is conserved between eukaryotic and prokaryotic cells. The Providencia stuartii Aar protein is a Rho-related protease that can functionally substitute the Drosophila Rho 8,9 . Additionally, eukaryotic Rho can complement a $P$. stuartii aar mutant, which shows that the function of these proteins is conserved between prokaryotes and eukaryotes. Rho is involved in signalling in animal cells, and Aar is also required for the production of a bacterial QS signal ${ }^{8,9}$. QS in $P$. stuartii represses the expression of an acetyl- 
transferase that modifies peptidoglycan (an intrinsic component of the bacterial cell wall) ${ }^{10}$, 11 .

\section{Signalling through GPCRs}

Another type of cell-surface receptor that can be activated by hormones is the GPCRs. These receptors have seven transmembrane domains and are coupled to heterotrimeric guaninebinding proteins (G proteins), which consist of an $\alpha$-, a $\beta$ - and a $\gamma$-subunit. Hormone binding to a GPCR results in a conformational change that induces the receptor to interact with a regulatory G protein; this stimulates the release of GDP in exchange for GTP and results in Gprotein activation. The activated $\mathrm{G}$ protein (bound to GTP) dissociates from the receptor, which is followed by $\alpha-\beta \gamma$ dissociation, and activates its intracellular target, which can be either an ion channel or an enzyme. GPCR specificity is controlled by the type of G protein with which a GPCR is associated. G proteins can be divided into four families depending on their association with different effector proteins. The signalling pathways of three of these $\mathrm{G} \alpha_{\mathrm{S}}, \mathrm{G} \alpha_{\mathrm{i}}$ and $\mathrm{G} \alpha_{\mathrm{q}}$ - have been extensively studied. The $\mathrm{G} \alpha_{\mathrm{S}}$ family activates adenylate cyclase, the $\mathrm{G} \alpha_{\mathrm{i}}$ family inhibits adenylate cyclase and the $\mathrm{G} \alpha_{\mathrm{q}}$ family activates phospholipase C. Within the largest class of the GPCRs are the mammalian adrenergic receptors, which change their conformation upon binding adrenaline or NA and thereby activate their coupled $\mathrm{G}$ protein to initiate a signalling cascade ${ }^{6}$ (FIG. 2).

Bacterial cells do not express adrenergic receptors, but many studies indicate that they respond to adrenaline and/or NA. Most of these studies were conducted in bacteria that inhabit the human gastrointestinal (GI) tract $5,12-26$, in which, notably, both adrenaline and NA are present. NA is synthesized in the adrenergic neurons of the enteric nervous system ${ }^{27}$. By contrast, adrenaline is synthesized in the central nervous system and the adrenal medulla; it acts in a systemic manner after being released into the bloodstream, thereby reaching the intestine $^{28}$. Although during homeostasis NA is probably the pre-dominant signal in the intestine (as it is produced in the enteric nervous system), during stress, adrenaline acts systemically and affects the whole body, including the human GI system ${ }^{28}$. Both hormones modulate intestinal smooth-muscle contraction, submucosal blood flow and chloride and potassium secretion in the intestine ${ }^{29}$. Freddolino and colleagues ${ }^{30}$ reported that the ligandbinding sites for adrenaline and NA in a human adrenergic receptor are similar, and there is evidence to indicate that both adrenaline and NA are recognized by the same receptors and have important biological roles in the human GI tract ${ }^{29}$. Furthermore, although these hormones are usually found at a nanomolar level in sera, the level of NA in the intestine is in the micromolar range; this is because the enteric nervous system is rich in adrenergic neurons, which have axon terminations that are close to the intestinal epithelia ${ }^{31}$.

\section{Interpreting adrenaline and NA}

Bacteria sense and respond to adrenaline and NA to regulate a multitude of phenotypes that range from metabolism to virulence-gene expression.

\section{EHEC as a case study: lessons from a hijacker}

NA induces bacterial growth, fimbriae and toxin expression in pathogenic Escherichia $\underline{c o l i}^{12-18}$. There are also reports in the literature (albeit conflicting) that imply that NA functions as a siderophore ${ }^{17,32}$. Recently, NA was implicated in the induced expression of enterobactin and iron uptake in E. coli, which suggests that this is the mechanism that is involved in growth induction ${ }^{18}$. However, the role of NA in bacterial pathogenesis seems to be more complex, and the line that divides signalling and iron uptake is becoming increasingly blurred; for example, the siderophore pyoverdine in Pseudomonas aeruginosa also acts as a signalling molecule ${ }^{33}$. It has also been reported that during surgical trauma NA release into 
the intestine induces the expression of virulence traits in $P$. aeruginosa, which leads to gutderived sepsis ${ }^{34}$. The role of adrenaline and NA signalling in bacterial pathogenesis was solidified by the discovery that both hormones induce the expression of flagella and the type III secretion system (T3SS) in the deadly pathogen enterohaemorrhagic E. coli (EHEC) O157:H7. EHEC can sense either the host adrenaline and NA or a bacterial aromatic QS signal, dubbed $\mathrm{AI} 3$, to express its virulence traits, which suggests that these host and bacterial signals are interchangeable ${ }^{5}$. EHEC are food-borne pathogens that cause major outbreaks of bloody diarrhoea and haemolytic uraemic syndrome throughout the world ${ }^{35}$. EHEC colonization of the large intestine causes attaching and effacing (AE) lesions on epithelial cells. These $\mathrm{AE}$ lesions are characterized by the destruction of microvilli and pedestal-like structures that 'cup' the bacterium ${ }^{36-38}$. The genes that are involved in the formation of the AE lesion are encoded by the locus of enterocyte effacement (LEE) chromosomal pathogenicity island 39 . The LEE region encodes a T3SS ${ }^{40}$, an adhesin ${ }^{41}$ and its receptor ${ }^{42}$, and effector proteins ${ }^{43}-47$. The mortality that is associated with EHEC infections stems from the production and release of potent Shiga toxin. Shiga toxin induces cell death in endothelial cells, primarily in the urinary tract, thereby causing haemolytic uraemic syndrome ${ }^{48}$.

EHEC sense three signals to activate their virulence genes - the bacterial signal AI-3, which is produced by several species of bacteria in the normal human GI microbial flora, and adrenaline and NA, both of which are produced by the host $5,25,49$. Recognition of these three signals is essential for in vivo virulence expression, as shown using rabbit and bovine infection models $^{23,50}$. AI-3, adrenaline and NA are agonistic signals, and responses to all three can be blocked by adrenergic antagonists $5,23,24$. These signals are sensed by the histidine sensor kinases in the membrane of EHEC that activate a complex regulatory cascade. This cascade culminates in the activation of genes that are necessary for motility, the expression of the LEE (which results in intestinal colonization through the formation of AE lesions) and Shiga-toxin expression $5,20,23,51$. QseC is one such sensor kinase.

\section{Signal interpretation through QseC and QseB}

QseC specifically senses AI-3, adrenaline and NA (to augment its phosphorylation state) by directly binding to these signals. Thus, $\mathrm{QseC}$ is a bacterial functional analogue of adrenergic receptors 23 . As a qseC mutant was attenuated for virulence in two rabbit animal models of infection $^{23}$ (v.S., unpublished observations), QseC is essential for full virulence in EHEC.

Typically, sensor kinases constitute two-component systems that act in concert with response regulators. In response to an environmental signal, the sensor autophosphorylates its own conserved histidine residue (FIG. 3). Subsequently, the histidine-bound phosphoryl group of the sensor kinase is transferred onto a specific aspartate residue on the cognate response regulator for activation. The activated response regulator then directly regulates the transcription of its target genes. In bacteria, the two-component system is the major system of signal transduction ${ }^{52}$. Importantly, mammals do not have histidine sensor kinases ${ }^{53,54}$. upon sensing AI3, adrenaline or NA, QseC phosphorylates the Qseb response regulator, which activates the expression of motility genes ${ }^{20}$ and itself ${ }^{19}$. In addition, QsebC plays an important part in the regulation of the LEE genes, ironuptake systems, several adhesins, other twocomponent systems and Shiga toxin (D.T.H. and v.S., unpublished observations). These in vitro and in vivo data suggest that $\mathrm{QseC}$ has a pivotal role in EHEC pathogenesis and interkingdom signalling. The QseC sensor is the first example of a receptor for both a bacterial and a host signal, and, therefore, QseC integrates bacteria-host signalling at the biochemical level.

QseC homologues are present in several other bacterial pathogens, including Salmonella

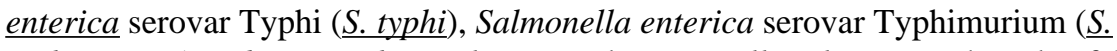
typhimurium), Vibrio parahaemolyticus and Francisella tularensis. The role of QseC in other bacterial pathogens is beginning to be elucidated. QseC regulates the expression of the PmrAb 
two-component system in S. typhimurium, which, in turn, regulates virulencegene expression $^{55}$. Also, a recent report demonstrated that a qseC mutant was defective in colonization of the swine GI tract ${ }^{56}$. The important role that sensing adrenaline and NA has during Salmonella spp. infection and colonization was further highlighted by a report that, in swine, either social stress or stress induced by transportation reactivates subacute Salmonella spp. infections and can increase the faecal excretion of these bacteria ${ }^{57}$. F . tularensis qseC mutants are attenuated for the infection of mice ${ }^{58}$. Although it has not been associated with QseC, NA has been shown to induce the expression of the $V$.

parahaemolyticus T3SS, cytotoxicity and pathogenicity in vivo, and these effects were blocked by adrenergic antagonists 26 . NA has also been shown to regulate the expression of the OspA protein in Borrelia burgdorferi, which is important for the survival of $\underline{B}$. burgdorferi in the tick host and its infection of mice ${ }^{59}$.

\section{Signal interpretation through QseE and QseF}

In EHEC, QseC autophosphorylation in response to the three signals that are discussed above can only be blocked by an $\alpha$-adrenergic antagonist (phentolamine) ${ }^{23}$. However, AE lesion formation can be blocked by a $\beta$-adrenergic antagonist (propranolol) 5 . These findings suggest that there is a second sensor for these signals. The interaction of AI3, adrenaline and NA with more than one sensor kinase could also provide a 'timing' mechanism during infection, which is desirable, as it would be inefficient for EHEC to express attachment and motility genes simultaneously. In addition to controlling the expression of the motility genes, the LEE and Shiga toxin, QseC also activates the transcription of a two-component system (QseEF), which is involved in $\mathrm{AE}$ lesion formation ${ }^{21}$. QseE is a membrane-bound sensor kinase, and QseF is its response regulator. Although the signals that are sensed by this two-component system have not yet been elucidated, the expression of $\mathrm{QseE}$ is essential for $\mathrm{AE}$ lesion formation by EHEC $^{21}$ and it could constitute a second adrenaline and/or NA sensor in E. coli.

\section{Al-3 signalling - talking back to the host?}

AI-3 is a bacterial signal that activates the expression of the EHEC virulence genes. AI-3 signalling in EHEC can be substituted by the hormones adrenaline and NA, which suggests that AI-3 might also be involved in inter kingdom signalling 5 . As the host hormones adrenaline and NA signal to EHEC, it would be expected that AI-3 can signal to eukaryotic cells. In the human intestine, enterocytes express the $\alpha_{2}$-adrenergic receptor. This receptor is expressed preferentially in the basolateral compartment of the polarized intestinal cells, but is also found in the brush border of these cells. It is expressed at higher levels in the proximal and transverse colon of the human intestine, which are, coincidently, the sites of microbial flora and EHEC colonization ${ }^{60}$. A general pathway of $\alpha_{2}$-adrenergic-signal transduction is the depression of intracellular cyclic AmP levels by the inhibition of adenylate cyclase. The $\alpha_{2}$-adrenergic receptor is coupled to both the $\mathrm{G}_{\mathrm{i}} 2$ and $\mathrm{G}_{\mathrm{i}} 3$ signalling proteins, and the activation of $\mathrm{G}_{\mathrm{i}} 2$ is predominantly responsible for the inhibition of adenylate cyclase by $\alpha_{2}$-agonists and natural ligands (adrenaline and NA) ${ }^{61}$. Future studies will investigate whether AI3 can inhibit adenylate cyclase through $\alpha_{2}$-adrenergic receptors in enterocytes. Such an inhibition would suggest that AI-3 functions in the human GI tract as a natural $\alpha$-agonist that is produced by the resident microbial flora. Given that $\alpha$-adrenergic agonists have been used extensively as inhibitors of chronic diarrhoea ${ }^{62}$, such an activity could suggest an important role for AI-3 in the maintenance of intestinal homeostasis.

\section{The stress response in inter-kingdom signalling}

Adaptations to environmental, psychosocial or physical insults in mammals are referred to as stress responses - also termed 'fight or flight' responses. The short-term activation of the stress response involves the synchronized interaction of all aspects of the neuroendocrine 
system, and ensures that energy substrates are available to meet the increasing energy demands of the body. Adrenaline and NA are classic stress hormones that have a pivotal role in the stress response ${ }^{6}$. Although they increase a mammals ability to respond to the environment, it seems that they can be sensed by bacteria, which allows these organisms to gauge the metabolic state of the host and exploit a weakened immune system. In addition to adrenaline and NA, the host releases endogenous opiods, such as dynorphin, during stress. A recent study suggested that the opportunistic pathogen $P$. aeruginosa uses host dynorphin to enhance the expression of its virulence traits; it was also shown that this mammalian stress hormone cross-signals with the $P$. aeruginosa QS signalling system ${ }^{63}$. Taken together, these studies have shown that there is an intricate connection between host stress signalling, bacterial QS and pathogenesis, which suggests that stress responses, some of the most basic physiological functions in prokaryotic and eukaryotic cells, are central to inter-kingdom communication.

\section{Communicating through intracellular receptors}

AHLs and AI1 are fatty-acid-based signalling molecules (FIG. 1; TABLE 1) that are synthesized by Gram-negative bacteria to coordinate the cell-density-based gene regulation that is known as QS. AHLs mediate bacterial processes by interacting with inducible transcriptional regulators. This process was first characterized in the bioluminescent bacterium Vibrio fischeri as a mechanism that regulates light production ${ }^{2}$. The role of AHLs as bacterial signalling molecules has since evolved to include many regulatory functions, including multiple mechanisms of bacterial pathogenesis ${ }^{64}$. These mechanisms are most extensively characterized in P. aeruginosa, in which AHLs are required to regulate colonization and persistence during infection 65,66 .

Lipidic-based or fatty-acid-based signalling mechanisms have also been extensively characterized in eukaryotes. Dozens of lipid-based hormones have been shown to facilitate hundreds of biological functions. These lipid-based molecules include members of the eicosanoid family as well as lipidic and steroid hormones. Lipid-based hormones diffuse freely across the cell membrane and interact with members of the nuclear hormone receptor family to modify transcriptional regulation 67 .

Bacterial AHLs and eukaryotic lipidic signalling molecules are chemically analogous and have comparable modes of action (FIG. 4). This observation led to the hypothesis that bacterial AIs enter the host cell and mediate the regulation of transcription ${ }^{68}$. A bona fide mammalian AHL receptor has not yet been found, but recent studies have shown that the AHL $N$-(3oxododecanoyl)-L-homoserine lactone (also known as OdDHL) can enter, and function in, mammalian cells 69 .

It has been known for more than a decade that AHLs can elicit responses in mammalian cells. This phenomenon was first observed using respiratory epithelial cells, in which there was a dose-dependent increase in interleukin (IL)-8 in response to purified $\mathrm{AHL}^{70}$. Subsequent reports indicated that AHLs have a pleiotropic effect on host cells that depends on cell type, AHL concentration and assay condition. However, several groups have consistently demonstrated what seems to be a biphasic role for AHLs in immunomodulation - low AHL concentrations impair the immune response, whereas high concentrations exacerbate immune function.

\section{Inhibition of the host immune response by AHLs}

AHLs were first shown to act as inhibitors of the host immune response in 1998 (REF. 4). In this study, it was reported that OdDHL inhibits lymphocyte proliferation and tumour necrosis factor- $\alpha$ production, and downregulates IL-12 production, in lipopolysaccharide-stimulated macrophages. This assay was used to establish the structural requirements of AHL for immune 
inhibition. Acylated L-homoserine lactones that have an 11-13 carbon side chain that contains either a 3-oxo or a 3-hydroxy group have optimal immune suppressive activity ${ }^{71}$. Subsequent studies indicated that OdDHL inhibits cytokine production in vitro and INF- $\gamma$ tends to be inhibited more than IL-4. However, in vivo experiments were suggestive of nonspecific immune inactivation rather than a T helper $1\left(\mathrm{~T}_{\mathrm{H}} 1\right)$ response ${ }^{72}$, which supports the finding that OdDHL inhibits the differentiation and proliferation of both $\mathrm{T}_{\mathrm{H}} 1$ and $\mathrm{T}_{\mathrm{H}} 2$ cells ${ }^{73,74}$.

\section{AHLs promote apoptosis}

Gram-negative bacteria, such as EHEC, enteropathogenic E. coli and Salmonella spp., secrete effectors to initiate apoptosis and abrogate the innate immune response ${ }^{75}$. Several recent reports indicate that OdDHL also initiates apoptosis, which suggests an additional mechanism of bacteria-mediated apoptosis. OdDHL causes apoptosis in various mammalian cell types, including neutrophils, macrophages, fibroblasts, human vascular endothelial cells and breast carcinoma cells $76-79$.

The induction of apoptosis by OdDHL was first observed by Tateda and colleagues ${ }^{76}$, who observed a dose-dependent and incubation-time-dependent increase in apoptosis in neutrophils and macrophages upon the addition of OdDHL. Interestingly, this effect was not observed upon the addition of $N$-butanoyl-L-homoserine lactone (also known as C4HSL), another QS molecule ${ }^{76}$. Structure-activity studies correlated the hydrophobicity of the side chain of OdDHL with its apoptotic activity. Several synthetic AHL analogues that had polar and nonpolar additions to the distal end of the side chain were tested in these correlation studies; the addition of polar groups abolished apoptotic activity, whereas the addition of bulky hydrophobic groups increased apoptotic activity 77 .

In 2004, the first clue towards understanding the mechanism that underlies AHL-induced apoptosis was provided ${ }^{79}$. In a breast carcinoma cell line, OdDHL diminished signal transduction and activator of transcription 3 (STAT3) activity, but had no effect on mAPK activity, and the pharmacological inhibition of the STAT3 pathway led to the same phenotype as the addition of OdDHL. Furthermore, the expression of a constitutively active STAT3 protein abolished the apoptotic activity of OdDHL ${ }^{79}$.

More recently, calcium signalling was established as a mechanism for OdDHL apoptotic activity 78 . OdDHL increases cytosolic calcium levels in murine fibroblasts and human vascular endothelial cells. Interestingly, the pharmacological inhibition of calcium signalling pathways abolishes the apoptotic effect of OdDHL, but the immunomodulatory effects of OdDHL remain intact ${ }^{78}$.

\section{AHLs elicit proinflammatory effects}

Following the discovery that IL 8 levels increase in respiratory epithelial cells upon the addition of OdDHL, a series of studies that documented numerous proinflammatory pathways that are affected by OdDHLs were published ${ }^{80}$. The first of these studies characterized the potential mechanism by which OdDHL could increase the production of IL-8. The transcription factors nuclear factor (NF)- $\mathrm{KB}$ and AP2 are required for maximal induction of I-L8 by OdDHL ${ }^{80}$. Furthermore, if the mAPK pathway is inhibited, OdDHL stimulation of both IL-8 and NF- $\mathrm{BB}$ is subdued 81 . However, OdDHL also induces neutrophil chemotaxis in an IL-8-independent manner ${ }^{80}$.

Subsequent studies examined the effect of OdDHL injection into the skin of mice. Injection resulted in increased mRNAs for the cytokines IL- $1 \alpha$ and IL- 6 as well as for the chemokines macrophage inflammatory protein 2 (mIP2), mIP1- $\beta$, interferon- $\gamma$ inducible protein 10 and Tcell activation gene 3 (REF. 82). OdDHL also activated T-cells to produce INF- $\gamma$ 82. 
Acting through the NF- $\kappa \mathrm{B}$ pathway, OdDHL increases the expression of cyclooxygenase 2 (COX2); an enzyme that is responsible for the synthesis of prostaglandin (an eicosanoid) ${ }^{83}$. Increased levels of membrane-associated prostaglandin E (PGE) synthase, as well as its product, PGE2, indicate that OdDHLs can act as potent activators of the lipid-mediated immune response. Prostaglandin metabolites, which are similar to OdDHL in structure and their chemical characteristics, have the same COX2 activation phenotype as OdDHLs; this indicates functionality through a common receptor ${ }^{83}$.

\section{On the forefront: novel roles for AHLs}

Rumbaugh ${ }^{84}$ has recently undertaken an unbiased approach to understanding the role of AHLs in mammalian cells. In this study, a microarray analysis of mouse fibro-blasts treated with OdDHL or C4-HSL was performed. Treatment with OdDHL and C4-HSL using Affymetrix GeneChips elicited significant changes in murine genes of $10 \%$ and $8 \%$, respectively. most of these differentially regulated genes exhibited AI specificity (regulated by either OdDHL or C4-HSL). Intriguingly, whereas several of these differentially regulated genes were from categories of previously discovered AHL targets, such as immune modulation and apoptosis, most of the differentially regulated genes were new AHL targets. Therefore, AHLs probably act on multiple mammalian pathways, and these interactions are probably not pathogenic in nature.

\section{Mammals fight back: destroying AHLs}

Recent studies have found cytoplasmic factors that degrade OdDHL, called paraoxonases (PONs), in mammalian cells 85,86 . PONs are involved in the detoxification of many organophosphates and act as lactonases 85,86 . Although it is possible that these functions evolved only to subvert the QS capabilities of an invading bacterium, this seems unlikely given that QS typically occurs outside the cell. It is more likely that these molecules evolved to prevent OdDHLs, which can infiltrate mammalian cells, from interfering with cellular functions.

In 2004, Chun and colleagues ${ }^{86}$ discovered that human airway epithelia inactivate OdDHL through an unknown mechanism, and activity is cell associated (that is, it is not a secreted factor). The likely candidates for the factor were subsequently reduced to the paraoxonase family proteins PON1, PON2 and PON3 (REFS 87,88). Although serum PON1 subverted $P$. aeruginosa $\mathrm{QS}$ and biofilm formation in vitro, Ponl-knockout mice were protected in a $P$. aeruginosa infection model. PON2 was eventually determined to be the most likely candidate for OdDHL degradation in mammals ${ }^{89}$. Tracheal epithelial-cell lysates from a Pon2-knockout mouse had impaired OdDHL-degrading activity, whereas overexpression of Pon 2 enhanced OdDHL degradation 90 . Lysates from Pon 1- and Pon3-knockout mice did not have impaired OdDHL-degrading activity 90 .

\section{AHL-binding domains share similarities with PAS and GAF domains}

Recent studies into the physical nature of AHL-binding domains have revealed structural similarities to PAS and GAF domains. The crystallization of TraR, an Agrobacterium tumefaciens QS protein, facilitated the first structural insights into the AHL-binding domain. The three-dimensional structure of TraR indicated that if bound to its ligand ( $\mathrm{N}$-(3-oxooctanoyl)-L-homoserine lactone) it shared structural similarities with the evolutionarily conserved PAS and GAF domains 91,92 . The recently solved structures of two other bacterial proteins that contain AHL-binding domains, LasR and SdiA, also showed that they share structural similarities with PAS and GAF domains ${ }^{93-96 .}$ 
The PAS and GAF domains are also found in the mammalian aryl hydrocarbon receptor (AhR), which shares functional similarities with bacterial AHL-induced transcription factors. AhR is a ligand-induced transcription factor that enters the nucleus and acts as a transcriptional regulator upon engagement by a hydrophobic molecule ${ }^{97}$. Other examples of mammalian PAS and GAF-domain-containing proteins include the neuronal carbon monoxide sensor NPAS2 (neuronal PAS domain protein 2), which regulates the mammalian circadian clock ${ }^{98}$, and HIF1 (hypoxiainducible factor 1), which regulates the hypoxic response ${ }^{97}$.

\section{Pathogens sense the host immune system}

The host immune system can use bacterial signals to gauge, and respond to, bacterial infections, but bacteria have also evolved the ability to sense and manipulate the host immune system. The $P$. aeruginosa OprF surface protein binds host interferon- $\gamma$ and initiates a signalling cascade in the bacterial cell that reprogrammes gene expression. It has been proposed that by this mechanism pathogens can detect if they have triggered the host innate immune response 99. In S. typhimurium, the PhoQ sensor kinase directly binds, and is activated by, host antimicrobial peptides. PhoQ then promotes the expression of virulence genes through a phosphorelay cascade ${ }^{100}$. These findings represent yet another molecular mechanism by which bacteria can sense small innate immune molecules and modulate virulence-gene expression.

\section{Bacteria-plant communications}

Many plant-specific pathogenic bacteria require QS to successfully mediate host infection ${ }^{101}$. However, plants and algae have evolved multiple mechanisms to interpret these QS signals and initiate defensive responses ${ }^{101}$. Nanomolar concentrations of AHLs cause substantial changes in protein expression in Medicago truncatula (alfalfa). Peptide-mass fingerprinting of 100 root proteins that were affected by AHLs revealed that $25 \%$ of these proteins had functions in host defence, whereas the remainder had roles in primary metabolism, plant-hormone responses, transcriptional regulation, protein processing and cytoskeletal activity 102 . Additionally, plants can respond differently to unique AHLs in a tissue-specific manner ${ }^{102}$. For example, during microarray analysis, the treatment of tomato-plant shoots with AHL resulted in the upregulation of multiple defence mechanisms 103 .

As a defence against pathogenic bacteria, plants and algae have mastered the art of AHL mimicry; they secrete hormones that mimic bacterial QS signals, which leads to confusion among the signalling bacteria. Interestingly, the secretion of these mimic compounds seems to be regulated by bacterial AHLs. For example, M. truncatula secretes more AHL mimics after bacterial AHL treatment ${ }^{102}$. Several groups have isolated and identified individual inhibitory mimic compounds. The most extensively studied are the halogenated furanones that are produced by the marine alga Delisea pulchra. D. pulchra furanones are structurally similar to bacterial AHLs. Furanones have been found to specifically inhibit AHL-regulated mechanisms in multiple bacterial species. In their natural marine environment, D. pulchra uses halogenated furanones to control the structure of the natural bacterial communities that are on the algal surface. The exact mechanism of action is unknown, but it is thought to increase the turnover of bacterial AHL-induced transcription factors ${ }^{104}$.

A detailed inhibitory mechanism has also been described in higher plants that have been infected with A. tumefaciens, the bacterium that causes crown gall tumours. Formation of these tumours requires plant-tissue injury. In the event of an injury, the plant facilitates the accumulation of $\gamma$-amino butyric acid (GAbA; also an animal neurotransmitter) near the wound. GAbA activates A. tumefaciens AttM lactonase, which causes the bacterium to destroy its own QS signal ${ }^{105}$. In addition, L-canavanine, produced by alfalfa, inhibits QS in the plant symbiont Sinorhizobium meliloti ${ }^{106}$. Furthermore, two compounds that were isolated from garlic inhibited QS in a LuxR reporter assay 107. 
However, bacteria-plant communication is not only necessary as a defence mechanism. One of the best-studied inter-kingdom signalling mechanisms is found in communications between Rhizobium spp. soil bacteria and their symbiotic legume hosts. In this system, legumes produce flavanoids, which are ligands for the bacterial NodD protein. Once activated, NodD activates the expression of other bacterial genes that encode Nod factors, which, in turn, activate plant root receptors and thereby initiate nodulation 108 .

\section{Evolution of cell-cell signalling}

Recently, an intriguing opinion was written by Iyer and colleagues 109 that examined the evolution of low-molecular-mass first-messenger metabolic pathways, including the synthesis of amino acids, amino-acid derivatives (NA, adrenaline, dopamine, serotonin and melatonin), nucleosides, histamine, lipid- and fatty-acid derivatives (acetylcholine) and inorganic molecules, such as carbon monoxide and nitric oxide ${ }^{109}$. They proposed that the evolution of cell-cell signalling in mammals relies more on late horizontal gene transfer from bacteria to animals than on vertical inheritance. This hypothesis was driven by the observation that the enzyme that regulates vertebrate melatonin biosynthesis, arylalkylamine $N$-acetyl-transferase, is encoded in bacteria, yeast and vertebrates, but not in plants, worms or flies ${ }^{110}$. They suggested that this pattern is consistent with an evolutionary mechanism that involves horizontal gene transfer and multiple gene losses. Of 17 major enzymes that are dedicated to messenger metabolism, only 2 are present in the 3 major crown-group lineages of eukaryotes (animals, plants and fungi) and in bacteria. Sixteen of these enzymes are present in animals and bacteria, and none of these enzymes is present in archaea, which share multiple vertically inherited core-gene sets with eukaryotes ${ }^{109}$. Additionally, the scattered distribution of these enzymes does not follow the distribution pattern of central metabolic genes, which generally are represented in all eukarya, bacteria and archaea. Interestingly, another enzyme that is involved in melatonin production, hydroxyindole $O$-methyltransferase, is found only in bacteria and vertebrates. Horizontal gene transfer indicates that bacteria and mammals have the same intrinsic ability to produce multiple mammalian signalling compounds. This argument substantiates a growing body of evidence 84 that bacteria produce small molecules for bacteriabacteria communication that also function directly in bacteria-host communication.

\section{Box 1 | Questions for future research}

- Do bacteria peptide hormones influence host signalling, and do host peptide hormones influence bacterial quorum sensing?

- Does autoinducer-3 signal to host cells, and if so, is this signalling adrenergic dependent?

- Are there more bacterial adrenergic receptors?

- What are the receptors for acyl-homoserine lactones in mammalian cells?

- Do bacterial cells sense steroid and lipidic mammalian hormones?

\section{Conclusion}

The inter-kingdom signalling field is in its infancy, but a growing body of work has demonstrated that inter-kingdom signalling has broad implications to evolution and for mammalian and plant health. Cross-signalling between bacterial AIs and host hormones are at the core of microbial-host communication. However, there are several questions to be answered (BOX 1), including whether bacterial peptide hormones and AI-3 also induce host signalling, and whether lipidic and/or steroid host hormones signal to bacteria. most of the 
receptors for these inter-kingdom signals in bacteria and their host also remain to be identified. Future studies in this field will enhance our understanding of the signalling networks that have driven the co-evolution of prokaryotes and eukaryotes. Furthermore, future studies may help us to exploit these communication systems for the design of novel therapeutics to combat bacterial infections and enhance host immune defences.

\section{Glossary}

Autoinducer, A bacterial hormone-like signalling molecule.; Enteric nervous system, A nervous system that innervates the gastrointestinal tract.; Siderophore, A small organic molecule that is produced by bacteria to sequester iron.; Type III secretion system, A specialized syringe-like secretion system that is used to inject bacterial effectors into host cells.; Haemolytic uraemic syndrome, A complication, caused mostly by Shiga toxin, that can cause the kidneys to shut down and results in high morbidity and mortality.; Enterocyte, An epithelial cell in the intestine.; Eicosanoid family, A lipid-based signalling molecule that is best known for its control of the immune response. Prostaglandins are part of the eicosanoid family.; $\mathrm{T}$ helper $1\left(\mathrm{~T}_{\mathrm{H}} 1\right)$ response, The actions of CD4 helper $\mathrm{T}$ lymphocytes can be summarized by two pathways, $\mathrm{T}_{\mathrm{H}} 1$ and $\mathrm{T}_{\mathrm{H}} 2$, on the basis of the cytokines that they produce and their effector functions. During the $\mathrm{T}_{\mathrm{H}} 1$ response, $\mathrm{T}$ helper lymphocytes principally secrete interferon- $\gamma$ to activate phagocyte-mediated defence, which typically involves intracellular microorganisms.; Paraoxonase family, A three-member gene family that consists of PON1, PON2 and PON3. Mammalian biological functions of paraoxonases remain elusive. However, possible functions include: protection from organophosphate poisoning; a protective role in vascular disease through lipoprotein lipid oxidation; and the limitation of bacterial infection through potential lactonase activity.; PAS and GAF domain, A ubiquitous protein motif that is conserved in prokaryotes and eukaryotes..

\section{References}

1. Hooper LV, Gordon JI. Commensal host- bacterial relationships in the gut. Science 2001;292:11151118. [PubMed: 11352068] Excellent review of the microbial regulation of host intestinal immune defence.

2. Nealson KH, Platt T, Hastings JW. Cellular control of the synthesis and activity of the bacterial luminescent system. J. Bacteriol 1970;104:313-322. [PubMed: 5473898]

3. Fuqua C, Winans SC, Greenberg EP. Census and consensus in bacterial ecosystems: the LuxR-LuxI family of quorum-sensing transcriptional regulators. Annu. Rev. Microbiol 1996;50:727-751. [PubMed: 8905097]

4. Telford G, et al. The Pseudomonas aeruginosa quorum-sensing signal molecule N-(3-oxododecanoyl)1-homoserine lactone has immunomodulatory activity. Infect. Immun 1998;66:36-42. [PubMed: 9423836]

5. Sperandio V, Torres AG, Jarvis B, Nataro JP, Kaper JB. Bacteria-host communication: the language of hormones. Proc. Natl Acad. Sci. USA 2003;100:8951-8956. [PubMed: 12847292] First description of adrenaline and NA regulation of the T3SS, and of motility and cross-talk with bacterial QS molecules.

6. Molina, PE. Endocrine Physiology. New York: The McGraw Hill Companies; 2006.

7. Moghal N, Sternberg PW. Multiple positive and negative regulators of signaling by the EGF-receptor. Curr. Opin. Cell Biol 1999;11:190-196. [PubMed: 10209155]

8. Gallio M, Sturgill G, Rather P, Kylsten P. A conserved mechanism for extracellular signaling in eukaryotes and prokaryotes. Proc. Natl Acad. Sci. USA 2002;99:12208-12213. [PubMed: 12221285]

9. Stevenson LG, et al. Rhomboid protease AarA mediates quorum-sensing in Providencia stuartii by activating TatA of the twin-arginine translocase. Proc. Natl Acad. Sci. USA 2007;104:1003-1008. [PubMed: 17215357] 
10. Rather PN, Parojcic MM, Paradise MR. An extracellular factor regulating expression of the chromosomal aminoglycoside $2^{\prime}-N$-acetyltransferase of Providencia stuartii. Antimicrob. Agents Chemother 1997;41:1749-1754. [PubMed: 9257754]

11. Rather PN, Ding X, Baca-DeLancey RR, Siddiqui S. Providencia stuartii genes activated by cell-tocell signaling and identification of a gene required for production or activity of an extracellular factor. J. Bacteriol 1999;181:7185-7191. [PubMed: 10572119]

12. Lyte M. The role of catecholamines in Gram-negative sepsis. Med. Hypotheses 1992;37:255-258. [PubMed: 1625603] First description of NA-inducing bacterial growth.

13. Lyte M, Ernst S. Catecholamine induced growth of Gram negative bacteria. Life Sci 1992;50:203212. [PubMed: 1731173]

14. Lyte M, Arulanandam BP, Frank CD. Production of Shiga-like toxins by Escherichia coli O157:H7 can be influenced by the neuroendocrine hormone norepinephrine. J. Lab. Clin. Med 1996;128:392398. [PubMed: 8833888]

15. Lyte M, et al. Norepinephrine-induced expression of the K99 pilus adhesin of enterotoxigenic Escherichia coli. Biochem. Biophys. Res. Commun 1997;232:682-686. [PubMed: 9126336]

16. Freestone PP, Haigh RD, Williams PH, Lyte M. Involvement of enterobactin in norepinephrinemediated iron supply from transferrin to enterohaemorrhagic Escherichia coli. FEMS Microbiol. Lett 2003;222:39-43. [PubMed: 12757944]

17. Freestone PP, et al. The mammalian neuroendocrine hormone norepinephrine supplies iron for bacterial growth in the presence of transferrin or lactoferrin. J. Bacteriol 2000;182:6091-6098. [PubMed: 11029429]

18. Burton CL, et al. The growth response of Escherichia coli to neurotransmitters and related catecholamine drugs requires a functional enterobactin biosynthesis and uptake system. Infect. Immun 2002;70:5913-5923. [PubMed: 12379665]

19. Clarke MB, Sperandio V. Transcriptional autoregulation by quorum sensing E. coli regulators B and C (QseBC) in enterohemorrhagic E. coli (EHEC). Mol. Microbiol 2005;58:441-455. [PubMed: 16194231]

20. Clarke MB, Sperandio V. Transcriptional regulation of $f l h D C$ by QseBC and $\sigma^{28}$ (FliA) in enterohaemorrhagic Escherichia coli. Mol. Microbiol 2005;57:1734-1749. [PubMed: 16135237] First description of a bacterial adrenergic receptor.

21. Reading NC, et al. A novel two-component signaling system that activates transcription of an enterohemorrhagic Escherichia coli effector involved in remodeling of host actin. J. Bacteriol 2007;189:2468-2476. [PubMed: 17220220]

22. Kendall MM, Rasko DA, Sperandio V. Global effects of the cell-to-cell signaling molecules autoinducer-2, autoinducer-3, and epinephrine in a luxS mutant of enterohemorrhagic Escherichia coli. Infect. Immun 2007;75:4875-4884. [PubMed: 17635870]

23. Clarke MB, Hughes DT, Zhu C, Boedeker EC, Sperandio V. The QseC sensor kinase: a bacterial adrenergic receptor. Proc. Natl Acad. Sci. USA 2006:10420-10425. [PubMed: 16803956]

24. Walters M, Sperandio VA. Autoinducer 3 and epinephrine signaling in the kinetics of locus of enterocyte effacement gene expression in enterohemorrhagic Escherichia coli. Infect. Immun 2006;74:5445-5455. [PubMed: 16988219]

25. Walters M, Sircili MP, Sperandio V. AI-3 synthesis is not dependent on luxS in Escherichia coli. J. Bacteriol 2006;188:5668-5681. [PubMed: 16885435]

26. Nakano M, Takahashi A, Sakai Y, Nakaya Y. Modulation of pathogenicity with norepinephrine related to the type III secretion system of Vibrio parahaemolyticus. J. Infect. Dis 2007;195:13531360. [PubMed: 17397007]

27. Furness JB. Types of neurons in the enteric nervous system. J. Auton. Nerv. Syst 2000;81:87-96. [PubMed: 10869706]

28. Purves, D., et al. Neuroscience. New York: Sinauer Associates; 2001.

29. Horger S, Schultheiss G, Diener M. Segment-specific effects of epinephrine on ion transport in the colon of the rat. Am. J. Physiol 1998;275:G1367-G1376. [PubMed: 9843774]

30. Freddolino PL, et al. Predicted 3D structure for the human $\beta 2$ adrenergic receptor and its binding site for agonists and antagonists. Proc. Natl Acad. Sci. USA 2004;101:2736-2741. [PubMed: 14981238] 
31. Eldrup E, Richter EA. DOPA, dopamine, and DOPAC concentrations in the rat gastrointestinal tract decrease during fasting. Am. J. Physiol. Endocrinol. Metab 2000;279:E815-E822. [PubMed: 11001763]

32. Kinney KS, Austin CE, Morton DS, Sonnenfeld G. Norepinephrine as a growth stimulating factor in bacteria — mechanistic studies. Life Sci 2000;67:3075-3085. [PubMed: 11125844]

33. Lamont IL, Beare PA, Ochsner U, Vasil AI, Vasil ML. Siderophore-mediated signaling regulates virulence factor production in Pseudomonas aeruginosa. Proc. Natl Acad. Sci. USA 2002;99:70727077. [PubMed: 11997446]

34. Alverdy J, et al. Gut-derived sepsis occurs when the right pathogen with the right virulence genes meets the right host: evidence for in vivo virulence expression in Pseudomonas aeruginosa. Ann. Surg 2000;232:480-489. [PubMed: 10998646]

35. Kaper, JB.; O’Brien, AD. Washington DC: ASM; 1998. Escherichia coli O157:H7 and other Shiga toxin-producing $E$. coli strains.

36. Moon HW, Whipp SC, Argenzio RA, Levine MM, Giannella RA. Attaching and effacing activities of rabbit and human enteropathogenic Escherichia coli in pig and rabbit intestines. Infect. Immun 1983;41:1340-1351. [PubMed: 6350186]

37. Knutton S, Baldini MM, Kaper JB, McNeish AS. Role of plasmid-encoded adherence factors in adhesion of enteropathogenic Escherichia coli to HEp-2 cells. Infect. Immun 1987;55:78-85. [PubMed: 2878887]

38. Tzipori S, et al. The pathogenesis of hemorrhagic colitis caused by Escherichia coli $\mathrm{O} 157: \mathrm{H} 7$ in gnotobiotic piglets. J. Infect. Dis 1986;154:712-716. [PubMed: 3528323]

39. McDaniel TK, Jarvis KG, Donnenberg MS, Kaper JB. A genetic locus of enterocyte effacement conserved among diverse enterobacterial pathogens. Proc. Natl Acad. Sci. USA 1995;92:1664-1668. [PubMed: 7878036]

40. Jarvis KG, et al. Enteropathogenic Escherichia coli contains a putative type III secretion system necessary for the export of proteins involved in attaching and effacing lesion formation. Proc. Natl Acad. Sci. USA 1995;92:7996-8000. [PubMed: 7644527]

41. Jerse AE, Yu J, Tall BD, Kaper JB. A genetic locus of enteropathogenic Escherichia coli necessary for the production of attaching and effacing lesions on tissue culture cells. Proc. Natl Acad. Sci. USA 1990;87:7839-7843. [PubMed: 2172966]

42. Kenny B, et al. Enteropathogenic E. coli (EPEC) transfers its receptor for intimate adherence into mammalian cells. Cell 1997;91:511-520. [PubMed: 9390560]

43. McNamara BP, Donnenberg MS. A novel proline-rich protein, EspF, is secreted from enteropathogenic Escherichia coli via the type III export pathway. FEMS Microbiol. Lett 1998;166:71-78. [PubMed: 9741085]

44. Kenny B, Jepson M. Targeting of an enteropathogenic Escherichia coli (EPEC) effector protein to host mitochondria. Cell. Microbiol 2000;2:579-590. [PubMed: 11207610]

45. Elliott SJ, et al. EspG, a novel type III system-secreted protein from enteropathogenic Escherichia coli with similarities to VirA of Shigella flexneri. Infect. Immun 2001;69:4027-4033. [PubMed: 11349072]

46. Tu X, Nisan I, Yona C, Hanski E, Rosenshine I. EspH, a new cytoskeleton-modulating effector of enterohaemorrhagic and enteropathogenic Escherichia coli. Mol. Microbiol 2003;47:595-606. [PubMed: 12535063]

47. Kanack KJ, Crawford JA, Tatsuno I, Karmali MA, Kaper JB. SepZ/EspZ is secreted and translocated into HeLa cells by the enteropathogenic Escherichia coli type III secretion system. Infect. Immun 2005;73:4327-4337. [PubMed: 15972527]

48. Karmali MA, Petric M, Lim C, Fleming PC, Steele BT. Escherichia coli cytotoxin, haemolyticuraemic syndrome, and haemorrhagic colitis. Lancet 1983;2:1299-1300. [PubMed: 6139632]

49. Tannock GW, et al. Ecological behavior of Lactobacillus reuteri 100-23 is affected by mutation of the luxS gene. Appl. Environ. Microbiol 2005;71:8419-8425. [PubMed: 16332830]

50. Vlisidou I, et al. The neuroendocrine stress hormone norepinephrine augments Escherichia coli O157:H7-induced enteritis and adherence in a bovine ligated ileal loop model of infection. Infect. Immun 2004;72:5446-5451. [PubMed: 15322043] 
51. Sperandio V, Torres AG, Giron JA, Kaper JB. Quorum sensing is a global regulatory mechanism in enterohemorrhagic Escherichia coli O157:H7. J. Bacteriol 2001;183:5187-5197. [PubMed: 11489873]

52. Igo MM, Ninfa AJ, Stock JB, Silhavy TJ. Phosphorylation and dephosphorylation of a bacterial transcriptional activator by a transmembrane receptor. Genes Dev 1989;3:1725-1734. [PubMed: 2558046]

53. Lyon GJ, Muir TW. Chemical signaling among bacteria and its inhibition. Chem. Biol 2003;10:10071021. [PubMed: 14652068]

54. Roychoudhury S, et al. Inhibitors of two-component signal transduction systems: inhibition of alginate gene activation in Pseudomonas aeruginosa. Proc. Natl Acad. Sci. USA 1993;90:965-969. [PubMed: 8381538]

55. Merighi M, Carroll-Portillo A, Septer AN, Bhatiya A, Gunn JS. Role of Salmonella enterica serovar Typhimurium two-component system PreA/PreB in modulating PmrA-regulated gene transcription. J. Bacteriol 2006;188:141-149. [PubMed: 16352830]

56. Bearson BL, Bearson SM. The role of the QseC quorum-sensing sensor kinase in colonization and norepinephrine-enhanced motility of Salmonella enterica serovar Typhimurium. Microb. Pathog 2007 Oct; 12

57. Callaway TR, et al. Social stress increases fecal shedding of Salmonella typhimurium by early weaned piglets. Curr. Issues Intest. Microbiol 2006;7:65-71. [PubMed: 16875421]

58. Weiss DS, et al. In vivo negative selection screen identifies genes required for Francisella virulence. Proc. Natl Acad. Sci. USA 2007;104:6037-6042. [PubMed: 17389372]

59. Scheckelhoff MR, Telford SR, Wesley M, Hu LT. Borrelia burgdorferi intercepts host hormonal signals to regulate expression of outer surface protein A. Proc. Natl Acad. Sci. USA 2007;104:72477252. [PubMed: 17438273]

60. Valet $P$, et al. Characterization and distribution of $\alpha_{2}$-adrenergic receptors in the human intestinal mucosa. J. Clin. Invest 1993;91:2049-2057. [PubMed: 8098045]

61. Remaury A, Larrouy D, Daviaud D, Rouot B, Paris H. Coupling of the $\alpha_{2}$-adrenergic receptor to the inhibitory G-protein $\mathrm{G}_{\mathrm{i}}$ and adenylate cyclase in HT29 cells. Biochem. J 1993;292:283-288. [PubMed: 8099279]

62. Buchman AL, et al. Clonidine reduces diarrhea and sodium loss in patients with proximal jejunostomy: a controlled study. J. Parenter. Enteral. Nutr 2006;30:487-491.

63. Zaborina O, et al. Dynorphin activates quorum sensing quinolone signaling in Pseudomonas aeruginosa. PLoS Pathog 2007;3:e35. [PubMed: 17367209] First report of the dynorphin regulation of bacterial pathogenesis and cross-signalling with QS.

64. Reading NC, Sperandio V. Quorum sensing: the many languages of bacteria. FEMS Microbiol. Lett 2006;254:1-11. [PubMed: 16451172]

65. Yoon SS, et al. Pseudomonas aeruginosa anaerobic respiration in biofilms: relationships to cystic fibrosis pathogenesis. Dev. Cell 2002;3:593-603. [PubMed: 12408810]

66. Singh PK, et al. Quorum-sensing signals indicate that cystic fibrosis lungs are infected with bacterial biofilms. Nature 2000;407:762-764. [PubMed: 11048725]

67. Downward J. The ins and outs of signalling. Nature 2001;411:759-762. [PubMed: 11459043]

68. Shiner EK, Rumbaugh KP, Williams SC. Inter-kingdom signaling: deciphering the language of acyl homoserine lactones. FEMS Microbiol. Rev 2005;29:935-947. [PubMed: 16219513]

69. Williams SC, et al. Pseudomonas aeruginosa autoinducer enters and functions in mammalian cells. J. Bacteriol 2004;186:2281-2287. [PubMed: 15060029]

70. DiMango E, Zar HJ, Bryan R, Prince A. Diverse Pseudomonas aeruginosa gene products stimulate respiratory epithelial cells to produce interleukin-8. J. Clin. Invest 1995;96:2204-2210. [PubMed: 7593606]

71. Chhabra SR, et al. Synthetic analogues of the bacterial signal (quorum sensing) molecule $N$-(3oxododecanoyl)-1-homoserine lactone as immune modulators. J. Med. Chem 2003;46:97-104. [PubMed: 12502363]

72. Ritchie AJ, Yam AO, Tanabe KM, Rice SA, Cooley MA. Modification of in vivo and in vitro T- and B-cell-mediated immune responses by the Pseudomonas aeruginosa quorum-sensing molecule $N$ (3-oxododecanoyl)-1-homoserine lactone. Infect. Immun 2003;71:4421-4431. [PubMed: 12874321] 
73. Ritchie AJ, et al. The Pseudomonas aeruginosa quorum-sensing molecule $N$-3-(oxododecanoyl)-1homoserine lactone inhibits T-cell differentiation and cytokine production by a mechanism involving an early step in T-cell activation. Infect. Immun 2005;73:1648-1655. [PubMed: 15731065]

74. Pritchard DI, et al. Alleviation of insulitis and moderation of diabetes in NOD mice following treatment with a synthetic Pseudomonas aeruginosa signal molecule, $N$-(3-oxododecanoyl)-1homoserine lactone. Acta Diabetol 2005;42:119-122. [PubMed: 16258734]

75. Mota LJ, Cornelis GR. The bacterial injection kit: type III secretion systems. Ann. Med 2005;37:234249. [PubMed: 16019722]

76. Tateda K, et al. The Pseudomonas aeruginosa autoinducer $N$-3-oxododecanoyl homoserine lactone accelerates apoptosis in macrophages and neutrophils. Infect. Immun 2003;71:5785-5793. [PubMed: 14500500]

77. Horikawa M, et al. Synthesis of Pseudomonas quorum-sensing autoinducer analogs and structural entities required for induction of apoptosis in macrophages. Bioorg. Med. Chem. Lett 2006;16:21302133. [PubMed: 16460931]

78. Shiner EK, et al. Pseudomonas aeruginosa autoinducer modulates host cell responses through calcium signalling. Cell. Microbiol 2006;8:1601-1610. [PubMed: 16984415]

79. Li L, Hooi D, Chhabra SR, Pritchard D, Shaw PE. Bacterial $N$-acylhomoserine lactone-induced apoptosis in breast carcinoma cells correlated with down-modulation of STAT3. Oncogene 2004;23:4894-4902. [PubMed: 15064716]

80. Zimmermann $\mathrm{S}$, et al. Induction of neutrophil chemotaxis by the quorum-sensing molecule $\mathrm{N}$-(3oxododecanoyl)-1-homoserine lactone. Infect. Immun 2006;74:5687-5692. [PubMed: 16988244]

81. Smith RS, et al. IL-8 production in human lung fibroblasts and epithelial cells activated by the Pseudomonas autoinducer $N$-3-oxododecanoyl homoserine lactone is transcriptionally regulated by NF- $\kappa$ B and activator protein-2. J. Immunol 2001;167:366-374. [PubMed: 11418672]

82. Smith RS, Harris SG, Phipps R, Iglewski B. The Pseudomonas aeruginosa quorum-sensing molecule $\mathrm{N}$-(3-oxododecanoyl)homoserine lactone contributes to virulence and induces inflammation in vivo. J. Bacteriol 2002;184:1132-1139. [PubMed: 11807074]

83. Smith RS, Kelly R, Iglewski BH, Phipps RP. The Pseudomonas autoinducer $N$-(3-oxododecanoyl) homoserine lactone induces cyclooxygenase-2 and prostaglandin E2 production in human lung fibroblasts: implications for inflammation. J. Immunol 2002;169:2636-2642. [PubMed: 12193735]

84. Rumbaugh KP. Convergence of hormones and autoinducers at the host/pathogen interface. Anal. Bioanal. Chem 2007;387:425-435. [PubMed: 16912860]

85. Yang F, et al. Quorum quenching enzyme activity is widely conserved in the sera of mammalian species. FEBS Lett 2005;579:3713-3717. [PubMed: 15963993]

86. Chun CK, Ozer EA, Welsh MJ, Zabner J, Greenberg EP. Inactivation of a Pseudomonas aeruginosa quorum-sensing signal by human airway epithelia. Proc. Natl Acad. Sci. USA 2004;101:3587-3590. [PubMed: 14970327] First report of mammalian cell inactivation of bacterial AHLs.

87. Khersonsky O, Tawfik DS. Structure-reactivity studies of serum paraoxonase PON1 suggest that its native activity is lactonase. Biochemistry 2005;44:6371-6382. [PubMed: 15835926]

88. Draganov DI, et al. Human paraoxonases (PON1, PON2, and PON3) are lactonases with overlapping and distinct substrate specificities. J. Lipid Res 2005;46:1239-1247. [PubMed: 15772423] First report that PONs are responsible for AHL inactivation.

89. Ozer EA, et al. Human and murine paraoxonase 1 are host modulators of Pseudomonas aeruginosa quorum-sensing. FEMS Microbiol. Lett 2005;253:29-37. [PubMed: 16260097]

90. Stoltz DA, et al. Paraoxonase-2 deficiency enhances Pseudomonas aeruginosa quorum sensing in murine tracheal epithelia. Am. J. Physiol. Lung Cell. Mol. Physiol 2007;292:L852-L860. [PubMed: 17122353]

91. Zhang RG, et al. Structure of a bacterial quorum-sensing transcription factor complexed with pheromone and DNA. Nature 2002;417:971-974. [PubMed: 12087407] First crystal structure of the bacterial AHL receptor TraR.

92. Vannini A, et al. The crystal structure of the quorum sensing protein TraR bound to its autoinducer and target DNA. EMBO J 2002;21:4393-4401. [PubMed: 12198141] 
93. Yao Y, et al. Structure of the Escherichia coli quorum sensing protein SdiA: activation of the folding switch by acyl homoserine lactones. J. Mol. Biol 2006;355:262-273. [PubMed: 16307757]

94. Bottomley MJ, Muraglia E, Bazzo R, Carfi A. Molecular insights into quorum sensing in the human pathogen Pseudomonas aeruginosa from the structure of the virulence regulator LasR bound to its autoinducer. J. Biol. Chem 2007;282:13592-13600. [PubMed: 17363368]

95. Ho YS, Burden LM, Hurley JH. Structure of the GAF domain, a ubiquitous signaling motif and a new class of cyclic GMP receptor. EMBO J 2000;19:5288-5299. [PubMed: 11032796]

96. Harper SM, Neil LC, Gardner KH. Structural basis of a phototropin light switch. Science 2003;301:1541-1544. [PubMed: 12970567]

97. Gu YZ, Hogenesch JB, Bradfield CA. The PAS superfamily: sensors of environmental and developmental signals. Annu. Rev. Pharmacol. Toxicol 2000;40:519-561. [PubMed: 10836146]

98. Dioum EM, et al. NPAS2: a gas-responsive transcription factor. Science 2002;298:2385-2387. [PubMed: 12446832]

99. Wu L, et al. Recognition of host immune activation by Pseudomonas aeruginosa. Science 2005;309:774-777. [PubMed: 16051797]

100. Bader MW, et al. Recognition of antimicrobial peptides by a bacterial sensor kinase. Cell 2005;122:461-472. [PubMed: 16096064]

101. Bauer WD, Mathesius U. Plant responses to bacterial quorum sensing signals. Curr. Opin. Plant Biol 2004;7:429-433. [PubMed: 15231266]

102. Mathesius U, et al. Extensive and specific responses of a eukaryote to bacterial quorum-sensing signals. Proc. Natl Acad. Sci. USA 2003;100:1444-1449. [PubMed: 12511600] Extensive report of bacteria-plant cross-hormonal signalling.

103. Lugtenberg, B.; Tikhonovich, I.; Provorov, N., editors. Biology of Molecular Plant-Microbe Interactions. Vol. Vol. 4. Minnesota: IS-MPMI; 2004.

104. Manefield M, et al. Halogenated furanones inhibit quorum sensing through accelerated LuxR turnover. Microbiology 2002;148:1119-1127. [PubMed: 11932456]

105. Chevrot R, et al. GABA controls the level of quorum-sensing signal in Agrobacterium tumefaciens. Proc. Natl Acad. Sci. USA 2006;103:7460-7464. [PubMed: 16645034]

106. Keshavan ND, Chowdhary PK, Haines DC, Gonzalez JE. 1-Canavanine made by Medicago sativa interferes with quorum sensing in Sinorhizobium meliloti. J. Bacteriol 2005;187:8427-8436. [PubMed: 16321947]

107. Persson T, et al. Rational design and synthesis of new quorum-sensing inhibitors derived from acylated homoserine lactones and natural products from garlic. Org. Biomol. Chem 2005;3:253262. [PubMed: 15632967]

108. Perret X, Staehelin C, Broughton WJ. Molecular basis of symbiotic promiscuity. Microbiol. Mol. Biol. Rev 2000;64:180-201. [PubMed: 10704479]

109. Iyer LM, Aravind L, Coon SL, Klein DC, Koonin EV. Evolution of cell-cell signaling in animals: did late horizontal gene transfer from bacteria have a role? Trends Genet 2004;20:292-299. [PubMed: 15219393]

110. Coon SL, et al. Pineal serotonin $N$-acetyltransferase: expression cloning and molecular analysis. Science 1995;270:1681-1683. [PubMed: 7502081]

\section{Acknowledgements}

Work in the laboratory of V.S. is supported by the National Institutes of Health, The Ellison Medical Foundation and Burroughs Wellcome Fund. The authors thank M. Lyte for comments on this manuscript. They also apologize to the numerous investigators whose manuscripts could not be cited owing to space constraints. 


\section{Amines}

Structure unknown, aminated aromatic compound

Al-3

(bacteria)<smiles>CNCC(O)c1ccc(O)c(O)c1</smiles>

Adrenaline

(host)<smiles>NC[C@@H](O)c1ccc(O)c(O)c1</smiles>

Noradrenaline (host)

\section{Lipidic steroids}<smiles>CCCCCC(=O)CC(=O)N[C@H]1CCOC1=O</smiles>

$\mathrm{AHL}$

N-3-oxooctanoyl-Lhomoserine lactone (bacteria)<smiles>CC(=O)C1CCC2C3CCC4=CC(=O)CCC4(C)C3CCC12C</smiles>

Progesterone

(host)

\section{Cholesterol}

(host)

Figure 1. Chemical structures of bacterial and host signals

The bacterial signal autoinducer (AI)-3 is an aromatic aminated signal; its final structure is still unknown. Because AI-3 is, to a certain degree, hydrophobic, it is not thought to be able to cross the cell membrane. The bacterial signal acyl homoserine lactone (AHL) is composed of a conserved homoserine ring and a variable acyl chain, and usually can cross the cell membrane. The host hormones adrenaline and noradrenaline are cathecolamines that are synthesized from tyrosine and usually do not cross the cell membrane. The host signals progesterone and cholesterol are two examples of lipid host hormones that can cross the cell membrane and bind intracellular receptors. 


\section{a Receptor kinase}

Inactive

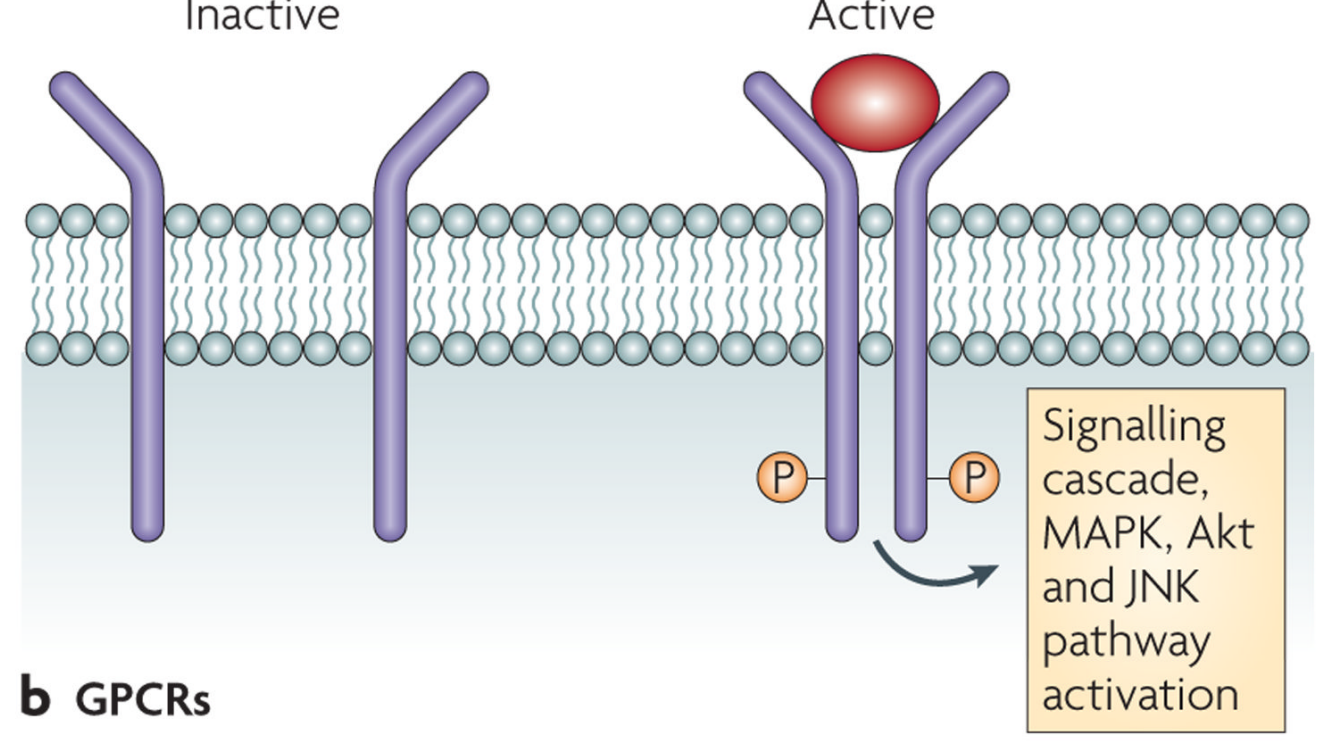

Active

Inactive

Active

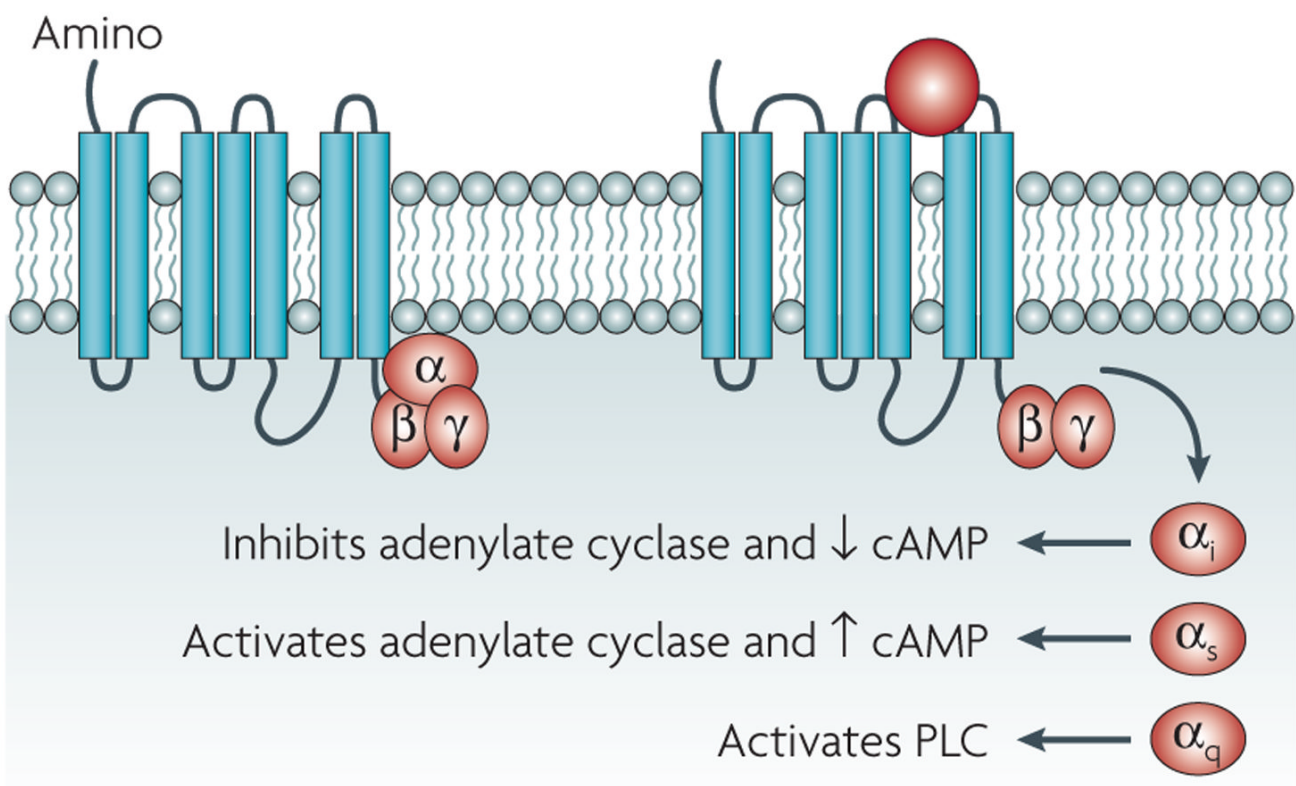

Figure 2. Mammalian signalling through membrane Receptors

a | Membrane receptor kinases dimerize and autophosphorylate a tyrosine or threonine residue upon binding to a hormone. They then initiate a phosphorelay signalling cascade in the cell. These cascades can include the mitogen-activated protein kinase (MAPK), Akt and Jun aminoterminal-kinase (JNK) pathways, and often lead to DNA synthesis and cell proliferation. b | G-protein-coupled receptors (GPCRs) are receptors that are coupled to guanine-binding proteins ( $G$ proteins) when they are inactive. G proteins consist of an $\alpha$-, a $\beta$ - and a $\gamma$-subunit. If a GPCR binds its signal (such as adrenaline or noradrenaline (NA)), the $\alpha$-subunit of the G protein is uncoupled and exerts its effect. Different families of the $\alpha$-subunit associate with different effectors and exert different effects. The $\alpha_{\mathrm{i}}$ inhibits adenylate cyclase and diminishes 
the levels of intracellular cyclic AMP (cAMP), the $\alpha_{\mathrm{s}}$ activates adenylate cyclase to increase the levels of cAMP and the $\alpha_{\mathrm{q}}$ activates phospholipase C (PLC). 


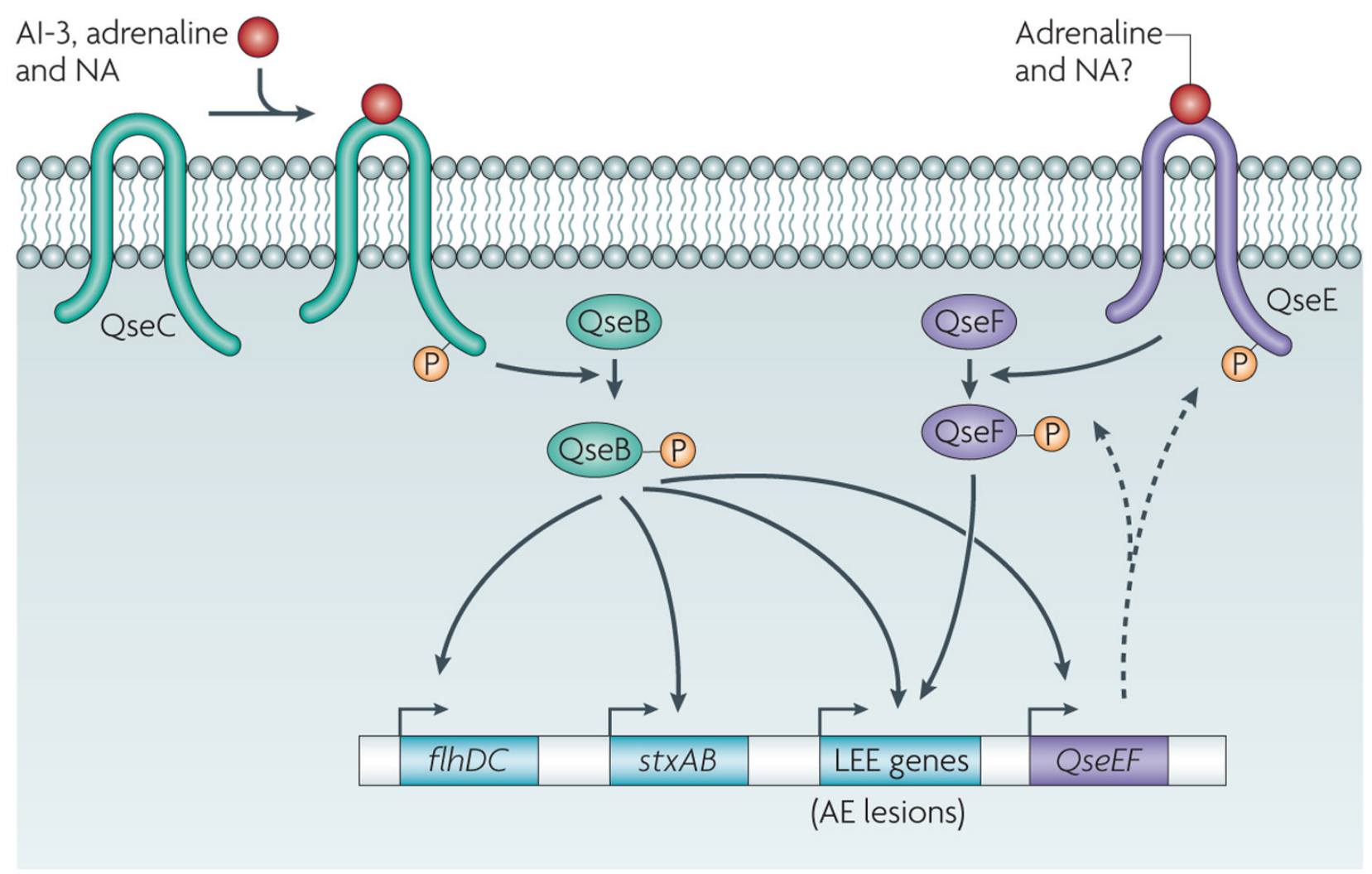

Figure 3. Adrenergic sensing in enterohaemorrhagic Escherichia coli

Autoinducer (AI)-3, adrenaline and noradrenaline (NA) bind the bacterial membrane receptor QseC, which results in its autophosphorylation. QseC then phosphorylates its response regulator QseB and initiates a complex phosphorelay signalling cascade that activates the expression of a second two-component system (QseEF), the locus of enterocyte effacement (LEE) genes (which encode various proteins, including the components of a type III section system that are involved in attaching and effacing (AE) lesion formation), the motility genes $(f l h D C)$ and Shiga toxin $(\operatorname{stx} A B)$. The QseEF two-component system is also involved in the expression of the LEE genes, and although its activators have not yet been elucidated, it is possible that it senses adrenaline and/or NA. 

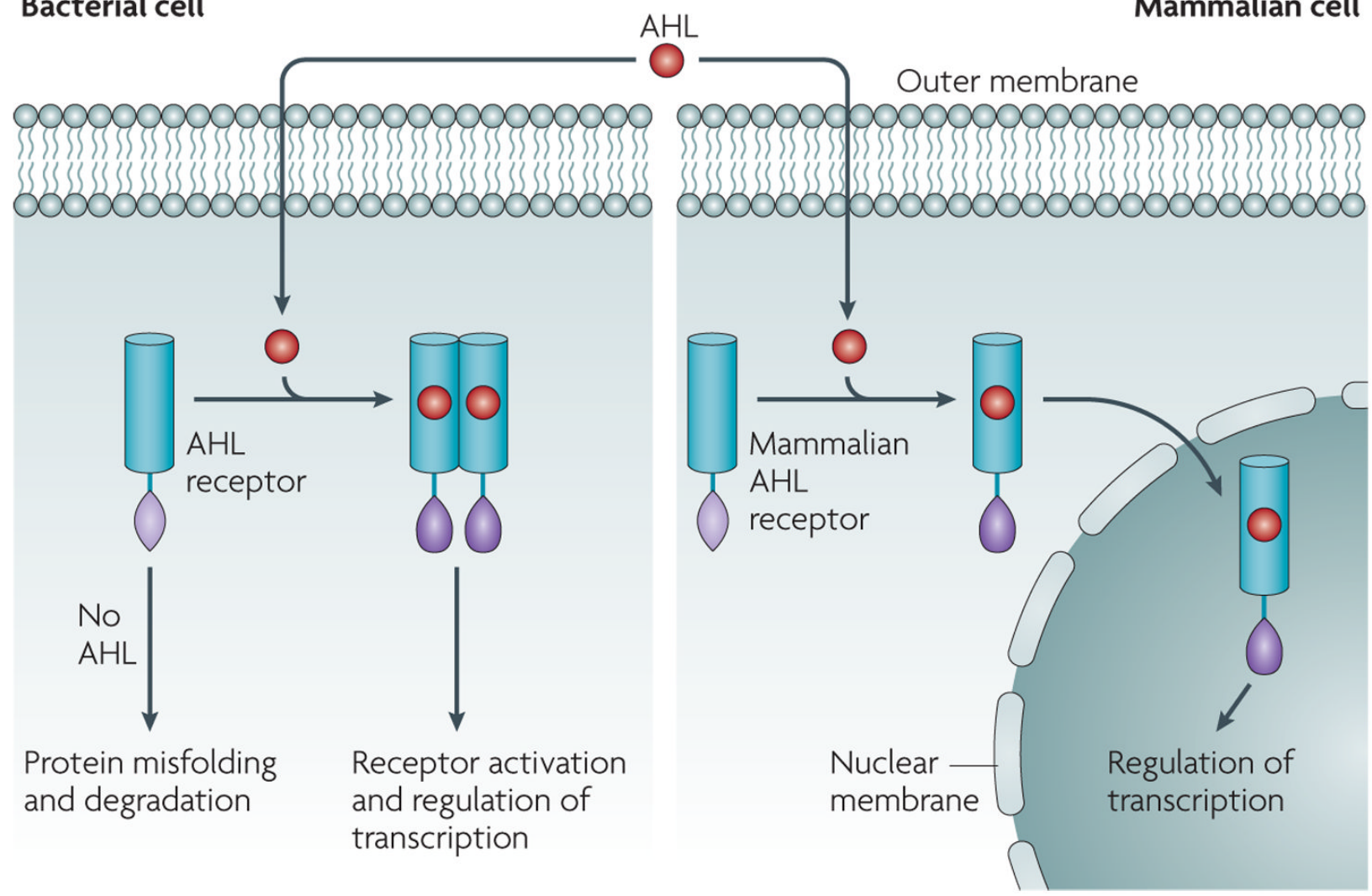

Figure 4. AHL inter-kingdom signaling

In bacteria, acyl homoserine lactones (AHLs) cross the cell membrane and interact with cytoplasmic receptors of the LuxR family. Binding the AHL to the LuxR-type receptor allows proper folding of this protein, which allows the receptor to dimerize and bind to its target sequence on DNA to regulate gene expression. In the absence of signal, LuxR-type proteins misfold and are targeted for degradation. In mammalian cells, AHLs also gain access to the cytoplasm by crossing the plasma membrane. The identity of the mammalian receptor (or receptors) for AHLs in mammalian cells is unknown. However, if there are intracellular receptors, it is proposed that the interaction with the AHL ligand activates these receptors and thereby allows their transportation into the nucleus, where they could control gene expression. 


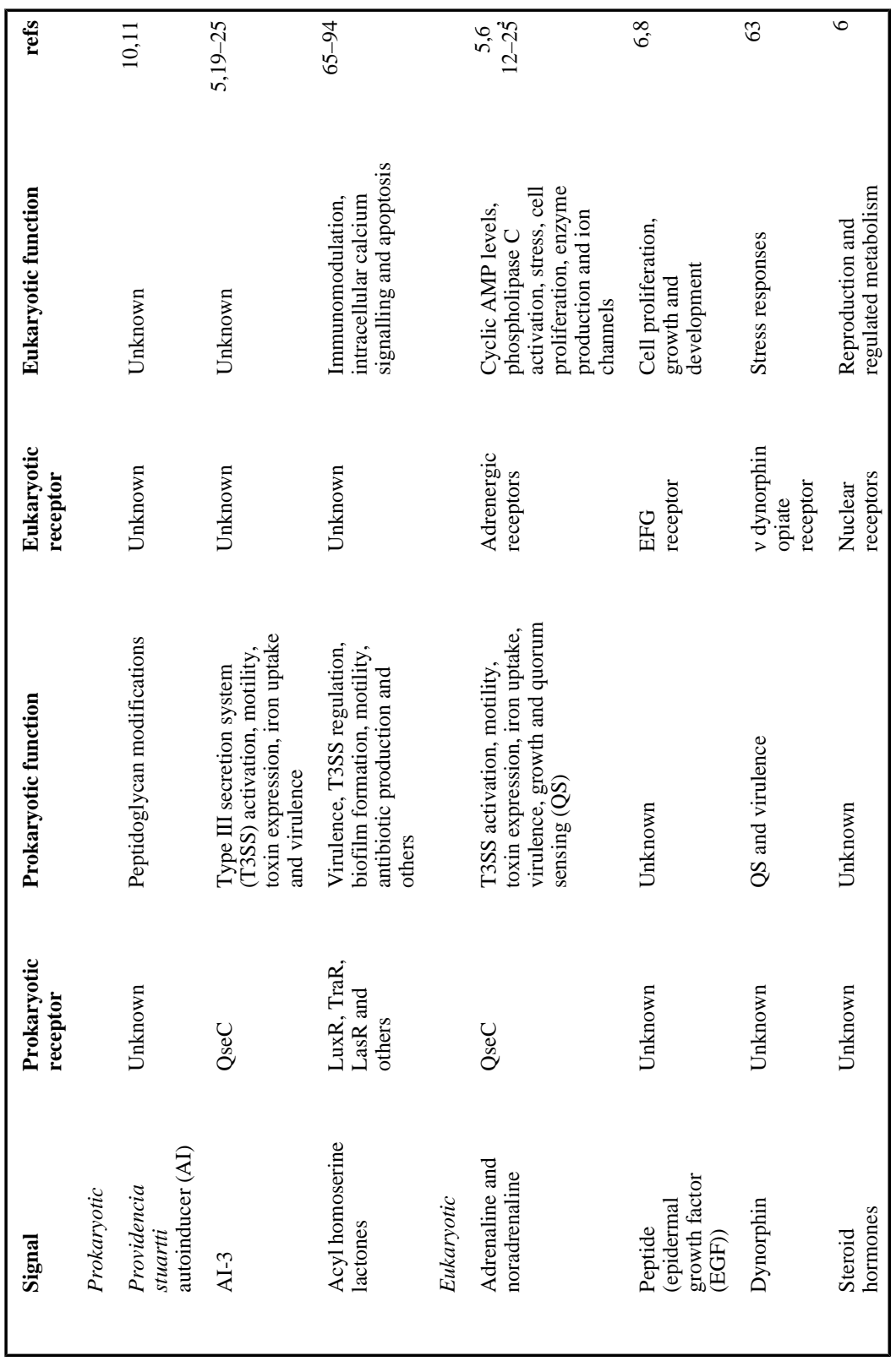

